\title{
Vertebral Augmentation in Patients with Multiple Myeloma: A Pooled Analysis of Published Case Series
}

\author{
O.A. Khan, W. Brinjikji, and D.F. Kallmes
}

\begin{abstract}
BACKGROUND AND PURPOSE: Studies examining the efficacy of vertebroplasty and kyphoplasty in patients with vertebral fractures from multiple myeloma are limited. We sought to perform a systematic review of published case studies examining changes in pain, disability, and analgesic drug use in patients with multiple myeloma who have undergone vertebral augmentation.
\end{abstract}

MATERIALS AND METHODS: We performed a pooled analysis of published case series of vertebral augmentation in patients with multiple myeloma. Twenty-three studies (9 kyphoplasty, 12 vertebroplasty, and 2 of both) with data on 923 patients were identified from a PubMed search. Quantitative outcome data included the Visual Analog Scale, the Brief Pain Inventory, the Short Form 36 Health Survey, and the Owestry Disability Index. Time periods were consolidated into 3: postoperatively $\leq 1$ week, 1 week to 1 year, and $\geq 1$ year. Change in analgesic use was also studied. Data were compared by using nonparametric tests and matched $t$ tests for temporally linked data.

RESULTS: Patients achieved a decrease in pain across all consolidated time periods. Pain, as measured on a 10-point scale, decreased by 4.8 points up to 1 week, 4.6 points up to 1 year, and 4.4 points after a year $(P<.001)$. Decrease in pain was apparent early after treatment and was sustained with time. Kyphoplasty and vertebroplasty were equally effective in reducing pain scores because differences between procedures for each time period were insignificant $(P<.9$ for $<1$ week, $P<1.0$ for $\leq 1$ year, and $P<.9$ for $>1$ year.

CONCLUSIONS: Our analysis demonstrates that vertebral augmentation is effective in patients with multiple myeloma.

ABBREVIATIONS: ODI = Owestry Disability Index

M ultiple myeloma is a neoplasm resulting from the proliferation of plasma cells which invade bone and release factors leading to bone fragility. ${ }^{1}$ Fifty-five to 70 percent of patients develop bony lesions that are localized primarily in the vertebrae. ${ }^{2}$ Vertebral augmentation has become an increasingly common treatment to alleviate pain caused by vertebral compression fractures. ${ }^{3}$ Randomized and nonrandomized controlled trials of patients with osteoporosis and solid metastatic neoplasms have shown that vertebroplasty and kyphoplasty reduce pain, decrease patient use of analgesic drugs, improve functional disability, and increase vertebral height. ${ }^{4-7}$ Complication rates are low, attributed commonly to cement leakage. ${ }^{8,9}$ Vertebroplasty and kyphoplasty are increasingly used to palliate vertebral lesions in myeloma. However, data are limited to small experiential case series.

Received February 17, 2013; accepted after revision April 8.

From the Departments of Radiology (O.A.K., W.B., D.F.K.) and Neurosurgery (D.F.K.), Mayo Clinic, Rochester, Minnesota.

Please address correspondence to Waleed Brinjikji, MD, Mayo Clinic, OL 1-115, 200 First St SW, Rochester, MN 55905; e-mail: brinjikji.waleed@mayo.edu

三 Indicates article with supplemental on-line tables.

http://dx.doi.org/10.3174/ajnr.A3622
We conducted a literature-based analysis of published case series. The aim was to compile and analyze data on vertebral augmentation procedures in multiple myeloma.

\section{MATERIALS AND METHODS Study Identification}

A review of the literature was performed by using PubMed. "Vertebroplasty" or "Kyphoplasty and Myeloma" were used as controlled vocabulary, and descriptors were identified by using MeSH. Studies of vertebroplasty and/or kyphoplasty published in the English language were considered in patients with myeloma, with a minimum of 15 patients, and those that contained $\geq 1$ of the following parameters: numeric pain assessment scores for pre- and postoperative pain (Visual Analog Scale, Brief Pain Inventory, Short Form 36 Health Survey), numeric Owestry Disability Index (ODI) assessment for preand postoperative disability, rate of cement leakage (as detected on CT and plain film), and change in patient analgesic drug use. A summary of our search strategy is provided in Fig 1.

\section{Data Extraction}

Data on pain, disability, and analgesic use were consolidated into 3 time periods: postoperatively $\leq 1$ week, $\leq 1$ year, and $>1$ year. The percentage of studies showing benefit and the extent of ben- 


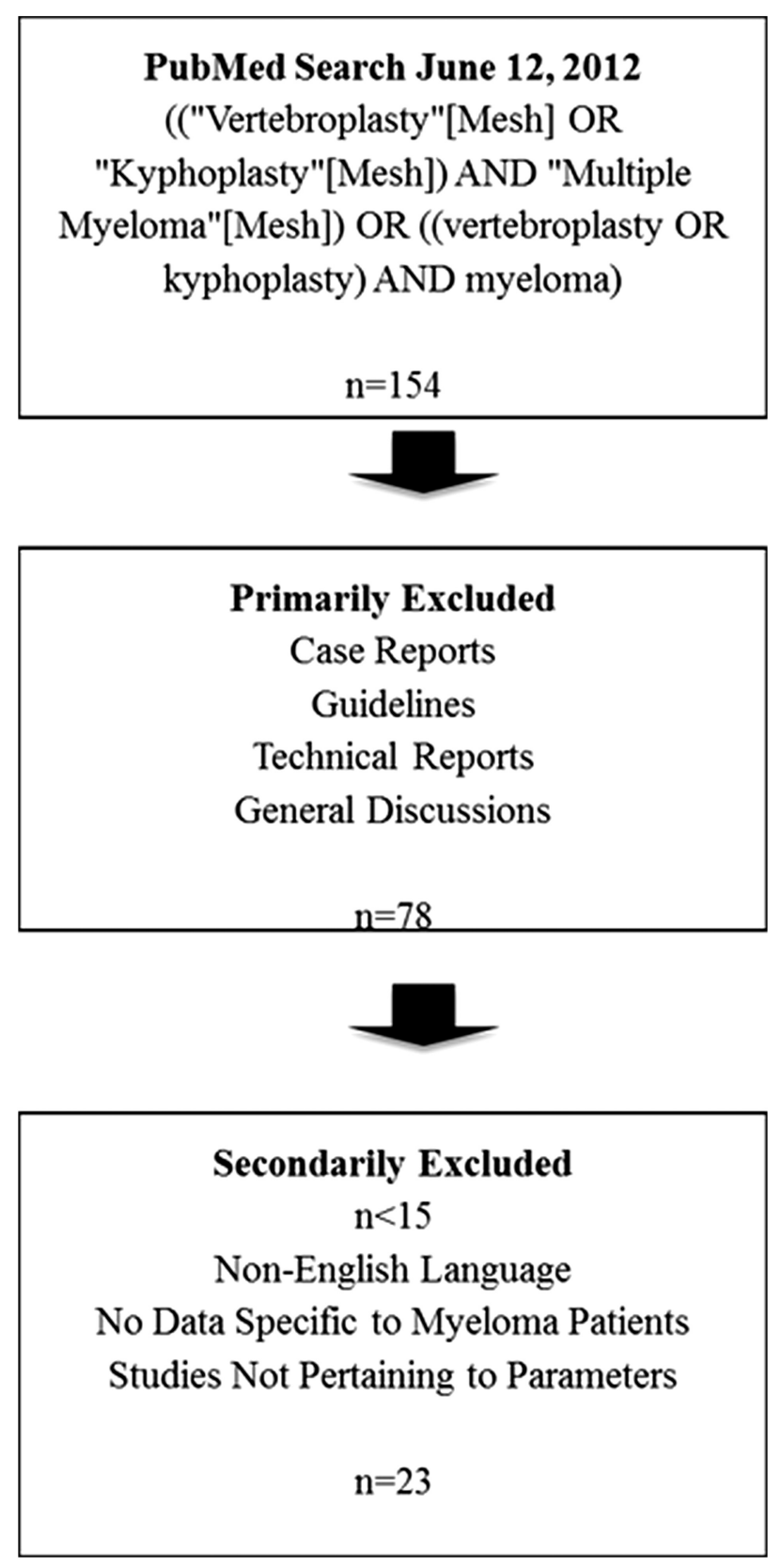

FIG 1. Search criteria used in PubMed data base.

efit were calculated. We looked for immediate or delayed benefit, and, if immediate, whether this benefit was sustained.

We collected data on the following complications: infection, pulmonary embolism, myocardial infarction, subsequent vertebral body compression fractures at untreated levels, neurologic symptoms requiring revision surgery, and transient postoperative pain. Outcome and complications rates of kyphoplasty were compared with those of vertebroplasty.

\section{Statistical Analysis}

Statistical analysis was performed by JMP software, Version 9 (SAS, Cary, North Carolina). For the purpose of descriptive and analytical analysis, mean scores were used (when unavailable, median scores were treated as means), and pain assessment from the Visual Analog Scale, the Short Form Health Survey 36, and the
Brief Pain Inventory was combined. Data were compared by using nonparametric tests ( $\chi^{2}$ and Wilcoxon rank tests). Matched $t$ tests for temporally linked data were used. Statistical significance was taken as a 2 -tailed $P$ value $<.05$.

\section{RESULTS}

There were 23 studies (9 kyphoplasty, 12 vertebroplasty, and 2 of both) with data on 923 patients. Twenty patients had multiple treatment sessions; thus, data on 943 procedures were extracted from the literature search. Of 22 studies that reported separate data on the 2 procedures, there were 367 kyphoplasty treatments and 576 vertebroplasty patients. Sex data were available for 760 patients (82.3\%). There were 215 men and 215 women for vertebroplasty studies, 153 men and 98 women for kyphoplasty studies, and 47 men and 32 women for a study that did not differentiate between the procedures. ${ }^{10}$ The mean age of the total patient population was 64.6 years (range, 28-92 years), while the mean age of patients who underwent kyphoplasty was 63.6 years (range, 28-90 years), and that of those who underwent vertebroplasty was 65.9 years (range, 35-92 years). These data are summarized in On-line Table 1. Spinal augmentation was performed on 1872 levels. Detailed anatomic localization of the fractures was not available. Data recorded in the studies ranged anywhere from 24 hours to 4 years postprocedure.

Nineteen studies reported on pre- and postprocedure pain (On-line Table 2). There was no significant difference in mean pain reduction between vertebroplasty and kyphoplasty at $\leq 1$ week ( 2.8 points \pm 0.4 versus 2.8 points $\pm 0.4, P=.9$ ). Similarly, no difference in pain reduction was found at 1 week to 1 year postprocedure as vertebroplasty patients had a mean pain reduction compared with baseline of 2.5 points \pm 0.4 versus 2.5 points \pm 0.5 for kyphoplasty patients $(P=1.00)$. At $>1$ year postprocedure, vertebroplasty patients had a mean pain reduction of 2.9 points \pm 0.6 compared with 2.7 points \pm 0.4 for kyphoplasty patients $(P=.9)$. When we combined pain outcomes of vertebroplasty and kyphoplasty patients, mean pain reduction at $\leq 1$ week postprocedure was 4.8 points $\pm 0.56(P<.001)$. This improvement in pain was sustained to $>1$ year postprocedure (mean pain reduction, 4.4 points $\pm 0.48 ; P<.001$ ). There was no significant reduction in pain when comparing postprocedural pain scores at different time points (Table 1).

Three studies reported ODI scores at $\leq 1$ week postprocedure, 6 studies reported ODI scores at 1 week to 1 year post procedure, and 4 studies reported ODI scores at $>1$ year postprocedure (Online Table 3 ). There was no significant decrease in ODI at $\leq 1$ week postprocedure (mean decrease of $39.2, P=.37$ ), at 1 week to 1 year postprocedure (mean decrease of $40.7, P=.14$ ), or at $>1$ year postprocedure (mean decrease of $46.5, P=.88$ ). Seven studies reported a percentage decrease in analgesic use at $\leq 1$ week postprocedure, 7 studies reported a percentage decrease in analgesic use at 1 week to 1 year postprocedure, and 3 studies reported a percentage decrease in analgesic use at $>1$ year postprocedure (On-line Table 4 ). There was a significant decrease in analgesic use at $\leq 1$ week postprocedure $(81.9 \%, P=.002)$ and at 1 week to 1 year postprocedure $(85.0 \%, P=.003)$. These data are summarized in Table 2 .

Cement leakage was detected with either plain film or CT. Twelve studies reported leakages in terms of the number of vertebral bodies, while 5 studies reported leakage in terms of the number of patients. Plain film identified 18\% (49/267, median $=0.15$, 


\begin{tabular}{|c|c|c|c|}
\hline Pain Comparison & No. of Studies & Mean Difference \pm SE & $P$ Value \\
\hline Preprocedure compared with $\leq 1$ week postprocedure & 11 & $4.8 \pm 0.56$ & $<.001$ \\
\hline Preprocedure compared with 1 week-1 year postprocedure & 14 & $4.6 \pm 0.49$ & $<.001$ \\
\hline Preprocedure compared with $>1$ year postprocedure & 14 & $4.4 \pm 0.48$ & $<.001$ \\
\hline$\leq 1$ Week postprocedure compared with 1 week-1 year postprocedure & 9 & $0.077 \pm 0.11$ & $<.481$ \\
\hline$\leq 1$ Week postprocedure compared with $>1$ year postprocedure & 7 & $0.49 \pm 0.49$ & $<.132$ \\
\hline 1 week-1 year postprocedure compared with $>1$ year postprocedure & 10 & $0.33 \pm 0.25$ & $<.276$ \\
\hline
\end{tabular}

Table 2: Change in ODI and analgesic use

\begin{tabular}{lcccc}
\hline & $\begin{array}{c}\text { Mean Decrease in ODI from } \\
\text { Baseline (range) }\end{array}$ & $\boldsymbol{P}$ & $\begin{array}{c}\text { \% Patients with Decrease } \\
\text { in Analgesic Drug Use from } \\
\text { Baseline (range) }\end{array}$ & $\boldsymbol{P}$ \\
\hline$\leq 1$ Week & $39.2(16.3-75.0)$ & .37 & $81.9(53.7-100)$ & .002 \\
1 Week-1 year & $40.7(16.3-75.0)$ & .14 & $85.0(46.1-100)$ & .003 \\
$>1$ Year & $46.5(14.5-75.0)$ & .88 & $89.1(57.7-100)$ & .08 \\
\hline
\end{tabular}

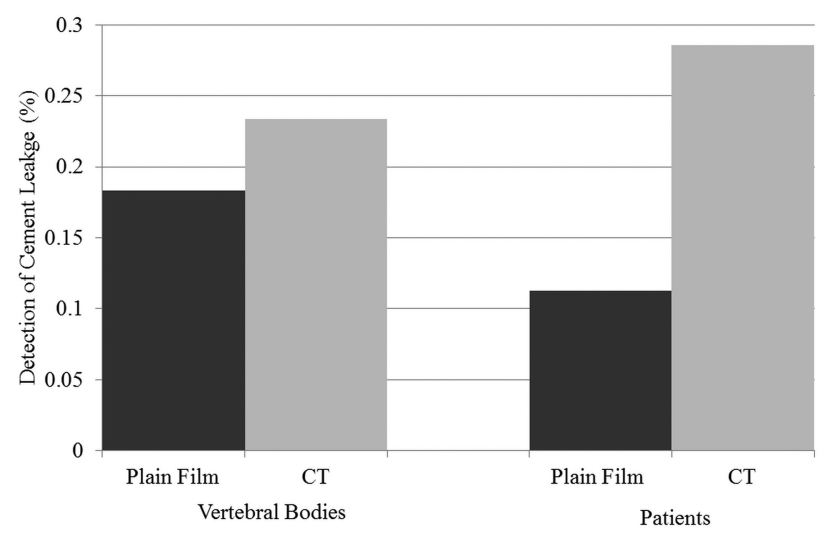

FIG 2. Detection of leakage with plain film versus CT.

range $=0.04-0.38)$ of vertebrae as having cement leakage, while CT identified 23\% (255/1090, median $=0.23$, range $=0.05-$ $0.49)$. When we considered studies that presented leakage in terms of the number of patients, plain film identified $11 \%(9 / 80$, median $=0.12$, range $=0.07-0.17)$ of patients as having leakage, while CT identified almost $29 \%(22 / 77$, median $=0.28$, range $=$ $0.03-0.53)$. CT in both cases was associated with more cases of leakage; however, the correlation was not significant (vertebrae $P$ value $=.75$, patient $P$ value $=1.0$ ). These data are summarized in Fig 2. Postprocedural pain score was not associated with cement leakage (coefficient $-0.096 \pm$ SE 1.34, $P=.9450$ ).

The most common complication was new vertebral fractures at untreated vertebral bodies. This occurred in $7.3 \%$ of vertebroplasty patients (42/576) and $6.8 \%$ of kyphoplasty patients (25/ 367). There was no difference in the rate of this complication between groups $(P=.78)$. Infection, pulmonary embolism, myocardial infarction, and neurologic symptoms requiring revision surgery occurred in $<1 \%$ of vertebroplasty and kyphoplasty patients. These data are summarized in Table 3.

\section{DISCUSSION}

Although vertebroplasty and kyphoplasty have been shown to be beneficial in patients with metastatic cancer and osteoporosis, studies depicting outcomes in patients with multiple myeloma are limited. Our analysis of published studies demonstrates that spinal augmentation in patients with myeloma is effective, with decreased postoperative pain and decreased analgesic drug use. The benefit was seen and efficacy rates in this study.

immediately on augmentation and was sustained for the duration of the reported follow-up periods (maximum of 4 years). We further demonstrated that complication rates associated with treatment of these patients are low; this finding suggests that treatment of these patients is safe. Vertebroplasty and kyphoplasty had similar safety

Randomized controlled trials have been performed for patients with osteoporosis or solid metastatic cancers who underwent spinal augmentation procedures. The treatment has consistently demonstrated decreased postoperative pain, disability, and analgesic use following vertebral augmentation procedures. ${ }^{4-7}$ Previous studies have shown that vertebroplasty and kyphoplasty differ in their postprocedure effectiveness. ${ }^{7}$ However, we did not find any statistically significant difference between the 2 procedures among patients with myeloma. Similar to patients with myeloma, those with osteoporosis also appeared to achieve early and sustained pain relief. ${ }^{11}$ Because the pain relief is generally achieved almost immediately postprocedure, it appears that the mechanism of benefit is anatomic (one hypothesis is that cement stabilization of vertebrae relieves pressure that fractures place on spinal nerves). ${ }^{3}$ There appears to be a similar percentage of decrease in pain scores for patients with osteoporotic compression fracture compared with those with multiple myeloma undergoing spine augmentation. ${ }^{4}$

When we studied cement leakage, simple cement leakage without other adverse events is generally not considered a complication but rather a stopping point for cement injection. While our study did show that CT is a superior means of detecting cement leakage, we do not advocate the routine use of CT for cement leakage detection because this is generally clinically irrelevant. Furthermore, most studies that include plain film follow-up only obtain frontal and lateral views. Oblique views are generally not obtained; this practice may limit the sensitivity of plain film in the detection of cement leakage.

\section{Limitations}

Intrinsic limitations of this review relate mainly to the design (including publication bias and use of studies that differed in adjunctive therapy, disease stage, and other factors) and the combined use of prospective and retrospective case series. Combining data that were reported differentially across studies required nonconventional compilation, which calls for uniformity in reporting future outcomes. The small sample size of relevant studies served as an additional limitation. Vertebral height was initially another parameter that was of interest to our study. However, a vast majority of studies did not report these data. An effort was made to contact authors but this proved to be unsuccessful. 


\begin{tabular}{|c|c|c|c|c|}
\hline Reported Symptomatic Complications & Overall Rate & Vertebroplasty Rate & Kyphoplasty Rate & $P$ \\
\hline Infection & $1 / 943$ & $1 / 576$ & $0 / 367$ & .64 \\
\hline Pulmonary embolism & $1 / 943$ & $0 / 576$ & $1 / 367$ & .21 \\
\hline Myocardial infarction & $1 / 943$ & $0 / 576$ & $1 / 367$ & .21 \\
\hline Vertebral body compression fractures at untreated levels & $67 / 943$ & $42 / 576$ & $25 / 367$ & .78 \\
\hline Neurologic symptoms requiring revision surgery & $2 / 943$ & $0 / 576$ & $2 / 367$ & .08 \\
\hline Transient perioperative pain & $6 / 943$ & $4 / 576$ & $2 / 367$ & .78 \\
\hline
\end{tabular}

\section{CONCLUSIONS}

This review served as a unique analysis of pooled data that demonstrated that vertebral augmentation is safe and effective in patients with multiple myeloma. Further prospective studies are needed to evaluate complication rates and confirm the immediate and sustained benefit of vertebral body augmentation in these patients.

Disclosures: David Kallmes_UNRELATED: Consultancy: ev3, ${ }^{*}$ Medtronic, ${ }^{*}$ Grants/ Grants Pending: MicroVention, ${ }^{*}$ ev3, ${ }^{*}$ Sequent Medical, ${ }^{*}$ Royalties: University of Virginia Patent Foundation, Travel/Accommodations/Meeting Expenses Unrelated to Activities Listed: MicroVention. * *Money paid to the institution.

\section{REFERENCES}

1. Edwards CM, Zhuang J, Mundy GR. The pathogenesis of the bone disease of multiple myeloma. Bone 2008;42:1007-13

2. Masala S, Fiori R, Massari F, et al. Percutaneous kyphoplasty: indications and technique in the treatment of vertebral fractures from myeloma. Tumori 2004;90:22-26

3. Mathis JM, Barr JD, Belkoff SM, et al. Percutaneous vertebroplasty: a developing standard of care for vertebral compression fractures. AJNR Am J Neuroradiol 2001;22:373-81

4. Papanastassiou ID, Phillips FM, Van Meirhaeghe J, et al. Comparing effects of kyphoplasty, vertebroplasty, and non-surgical management in a systematic review of randomized and non-randomized controlled studies. Eur Spine J 2012;21:1826-43

5. Rhyne A 3rd, Banit D, Laxer E, et al. Kyphoplasty: report of eightytwo thoracolumbar osteoporotic vertebral fractures. J Orthop Trauma 2004;18:294-99

6. McGirt MJ, Parker SL, Wolinsky JP, et al. Vertebroplasty and kyphoplasty for the treatment of vertebral compression fractures: an evidenced-based review of the literature. Spine J 2009;9:501-08

7. Han S, Wan S, Ning L, et al. Percutaneous vertebroplasty versus balloon kyphoplasty for treatment of osteoporotic vertebral compression fracture: a meta-analysis of randomised and non-randomised controlled trials. Int Orthop 2011;35:1349-58

8. Levine SA, Perin LA, Hayes D, et al. An evidence-based evaluation of percutaneous vertebroplasty. Manag Care 2000;9:56-60, 63

9. Bouza C, Lopez-Cuadrado T, Cediel P, et al. Balloon kyphoplasty in malignant spinal fractures: a systematic review and meta-analysis. BMC Palliat Care 2009;8:12

10. Mendoza TR, Koyyalagunta D, Burton AW, et al. Changes in pain and other symptoms in patients with painful multiple myelomarelated vertebral fracture treated with kyphoplasty or vertebroplasty. J Pain 2012;13:564-70

11. Gill JB, Kuper M, Chin PC, et al. Comparing pain reduction following kyphoplasty and vertebroplasty for osteoporotic vertebral compression fractures. Pain Physician 2007;10:583-90

12. Chen LH, Hsieh MK, Niu CC, et al. Percutaneous vertebroplasty for pathological vertebral compression fractures secondary to multiple myeloma. Arch Orthop Trauma Surg 2012;132:759-64

13. Yang Z, Tan J, Xu Y, et al. Treatment of MM-associated spinal fracture with percutaneous vertebroplasty (PVP) and chemotherapy. Eur Spine J 2012;21:912-19

14. Trumm C, Jakobs T, Pahl A, et al. CT fluoroscopy-guided percutaneous vertebroplasty in patients with multiple myeloma: analysis of technical results from 44 sessions with 67 vertebrae treated. $D i$ agn Interv Radiol 2012;18:111-20

15. Kasperk C, Haas A, Hillengass J, et al. Kyphoplasty in patients with multiple myeloma a retrospective comparative pilot study. J Surg Oncol 2012;105:679-86

16. Basile A, Cavalli M, Fiumara P, et al. Vertebroplasty in multiple myeloma with osteolysis or fracture of the posterior vertebral wall: usefulness of a delayed cement injection. Skeletal Radiol 2011;40:913-19

17. Anselmetti GC, Manca A, Montemurro F, et al. Percutaneous vertebroplasty in multiple myeloma: prospective long-term follow-up in 106 consecutive patients. Cardiovasc Intervent Radiol 2012;35:139-45

18. Masala S, Volpi T, Fucci FP, et al. Percutaneus osteoplasty in the treatment of extraspinal painful multiple myeloma lesions. Support Care Cancer 2011;19:957-62

19. Astolfi S, Scaramuzzo L, Logroscino CA. A minimally invasive surgical treatment possibility of osteolytic vertebral collapse in multiple myeloma. Eur Spine J 2009;18(suppl 1):115-21

20. Masala S, Anselmetti GC, Marcia S, et al. Percutaneous vertebroplasty in multiple myeloma vertebral involvement. J Spinal Disord Tech 2008;21:344-48

21. McDonald RJ, Trout AT, Gray LA, et al. Vertebroplasty in multiple myeloma: outcomes in a large patient series. AJNR Am J Neuroradiol 2008;29:642-48

22. Tran Thang NN, Abdo G, Martin JB, et al. Percutaneous cementoplasty in multiple myeloma: a valuable adjunct for pain control and ambulation maintenance. Support Care Cancer 2008;16:891-96

23. Köse KC, Cebesoy O, Akan B, et al. Functional results of vertebral augmentation techniques in pathological vertebral fractures of myelomatous patients. J Natl Med Assoc 2006;98:1654-58

24. Khanna AJ, Reinhardt MK, Togawa D, et al. Functional outcomes of kyphoplasty for the treatment of osteoporotic and osteolytic vertebral compression fractures. Osteoporos Int 2006;17:817-26

25. Pflugmacher R, Kandziora F, Schroeder RJ, et al. Percutaneous balloon kyphoplasty in the treatment of pathological vertebral body fracture and deformity in multiple myeloma: a one-year follow-up. Acta Radiol 2006;47:369-76

26. Bosnjaković $\mathrm{P}$, Ristic S, Mrvic M, et al. Management of painful spinal lesions caused by multiple myeloma using percutaneous acrylic cement injection. Acta Chir Iugosl 2009;56:153-58

27. Huber FX, McArthur N, Tanner M, et al. Kyphoplasty for patients with multiple myeloma is a safe surgical procedure: results from a large patient cohort. Clin Lymphoma Myeloma 2009;9:375-80

28. Zou J, Mei X, Gan M, et al. Kyphoplasty for spinal fractures from multiple myeloma. J Surg Oncol 2010;102:43-47

29. Julka A, Tolhurst SR, Srinivasan RC, et al. Functional outcomes and height restoration for patients with multiple myeloma-related osteolytic vertebral compression fractures treated with kyphoplasty. J Spinal Disord Tech 2012 Jun 1. [Epub ahead of print]

30. Lane JM, Hong R, Koob J, et al. Kyphoplasty enhances function and structural alignment in multiple myeloma. Clin Orthop Relat Res 2004;49-53

31. Garland P, Gishen P, Rahemtulla A. Percutaneous vertebroplasty to treat painful myelomatous vertebral deposits-long-term efficacy outcomes. Ann Hematol 2011;90:95-100

32. Lim BS, Chang UK, Youn SM. Clinical outcomes after percutaneous vertebroplasty for pathologic compression fractures in osteolytic metastatic spinal disease. J Korean Neurosurg Soc 2009;45:369-74

33. Dudeney S, Lieberman IH, Reinhardt MK, et al. Kyphoplasty in the treatment of osteolytic vertebral compression fractures as a result of multiple myeloma. J Clin Oncol 2002;20:2382-87 